\title{
MAJOR FACTORS INFLUENCING HIV/AIDS PROJECT EVALUATION
}

\author{
MERCY BI NIBA \\ J. MARYANN GREEN \\ University of KwaZulu-Natal, South Africa
}

\begin{abstract}
This article aimed at finding out if participatory processes (group discussions, enactments, and others) do make a valuable contribution in communication-based project implementation/ evaluation and the fight against HIV/AIDS. A case study backed by documentary analysis of evaluation reports and occasional insights from interviews stood as the main methods. To identify values, the state of beneficiaries prior to and after project implementation/evaluation was compared. Participatory processes were noted to have created an enabling environment for project beneficiaries to become activists for social change, leading to the limiting of the spread of HIV/ AIDS through sexual behavior and a change of attitude-the essence required for successful intervention. Group participatory processes were also noted to have contributed in overriding, to a great extent, limitations arising from sociodemographic differences in the attainment of project objectives and limitations arising from differences in forms of evaluation (internal versus external evaluators).
\end{abstract}

Keywords: HIV/AIDS; evaluations; participation; empowerment; interventions

This article seeks to find out if participatory processes do make a valuable contribution in project implementation/evaluation and the fight against HIV/ AIDS. These processes imply more than the mere presence of people on board but their active involvement in collectively taking control, developing plans of action, and responding to feedback in relation to future action. These processes could have implications for both interventions and their evaluations. As pointed out by Nutbeam (1998), a significant attempt is being made to understand the complexity of health promotion activities and the related need for sophisticated measures and evaluation research designs. A careful understanding of issues embodying evaluations, particularly those related to meaningful involvement by beneficiaries and other stakeholders in evaluation processes, could then be considered to be of vital importance. To this end, projects dealing with HIV/AIDS in a participatory manner were analyzed in terms of whether they added value to evaluation of communication-

EVALUATION REVIEW, Vol. 29 No. 4, August 2005 313-330

DOI: $10.1177 / 0193841 X 05276654$

(C) 2005 Sage Publications 
based projects and curbed the spread of and changed attitudes toward HIV/ AIDS.

Given the broadness of participation, whereby it can be argued that there is nothing about impact assessments or experiments that is nonparticipatory, analysis of participation was done with the understanding of group activities that include group discussions, situation enactments, and song and dance creations. These activities were argued to imply not the mere presence of people on board but their active involvement as a group and of people collectively taking control. Participatory processes in the implementation and evaluation of HIV/AIDS communication-based projects were examined to determine whether they created an enabling environment for project beneficiaries to become activists for social change leading to the limiting of the spread of HIV/AIDS through sexual behavior and the change of attitude: the essence required for successful intervention.

\section{REASON FOR THE STUDY}

The criteria for selection of the key issues of the study were based on literature that built an understanding of major processes influencing HIV/AIDS project evaluations. Given, however, the large number of works on participatory processes, only those closely linked to this study were included. These included works dealing with group knowledge acquisition, awareness, attitude change, empowerment, effective functioning, and sustainability. Communication-based projects were selected because they had social implications for the outcomes of the interventions. Other critical works, such as those of Bruyn (1998), Cohen and Manion (1989), and Musendo (2003) that handled developmental, organizational, and regional/national processes involving long-term communication and multisectoral strategies (legal services, human rights, land policies, and others), were not dealt with because they were outside the ambit of this study.

\section{METHOD USED FOR THE STUDY}

Figure 1 gives a breakdown of the methodological framework. The role of a participatory process supported by communication-based projects dealing with HIV/AIDS was provided and linked to develop a basis for further research. The value of such participatory processes was examined in the light of whether they made a difference in evaluation and the curbing of HIV/ 


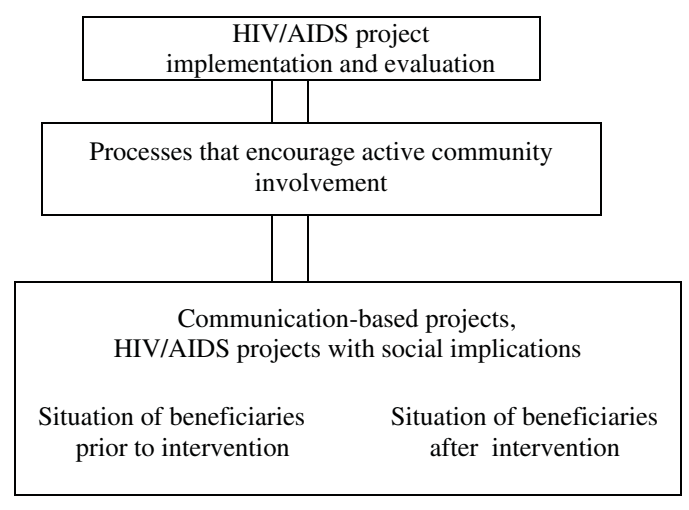

Figure 1: Methodological Framework

AIDS after implementation compared to when there was no intervention. To identify values, the opinions of beneficiaries prior to and after project implementation/evaluation were sought.

Documentary analysis of evaluation reports and occasional insights from interviews stood as the main methods of carrying out this portion of the study. Such analyses were advanced bearing in mind the following compounding variables that might have invariably affected (either positively or negatively) the outcomes of the projects studied and their evaluations:

- sociodemographic differences (gender, race, language, and age) of project implementers,

- evaluators and beneficiaries of the HIV/AIDS projects studied (and their evaluations),

- rural-urban differences of the HIV/AIDS projects studied (and their evaluations), and

- differences in the selection of evaluators (some projects having external evaluators and others internal evaluators) in the HIV/AIDS projects and their evaluations studied.

\section{IN-DEPTH CASE STUDIES OF THE PARTICIPATORY EVALUATION PROCESSES}

To provide a vivid picture of each of the studied HIV/AIDS evaluations, a brief description of each of the projects as a whole (from implementation to 


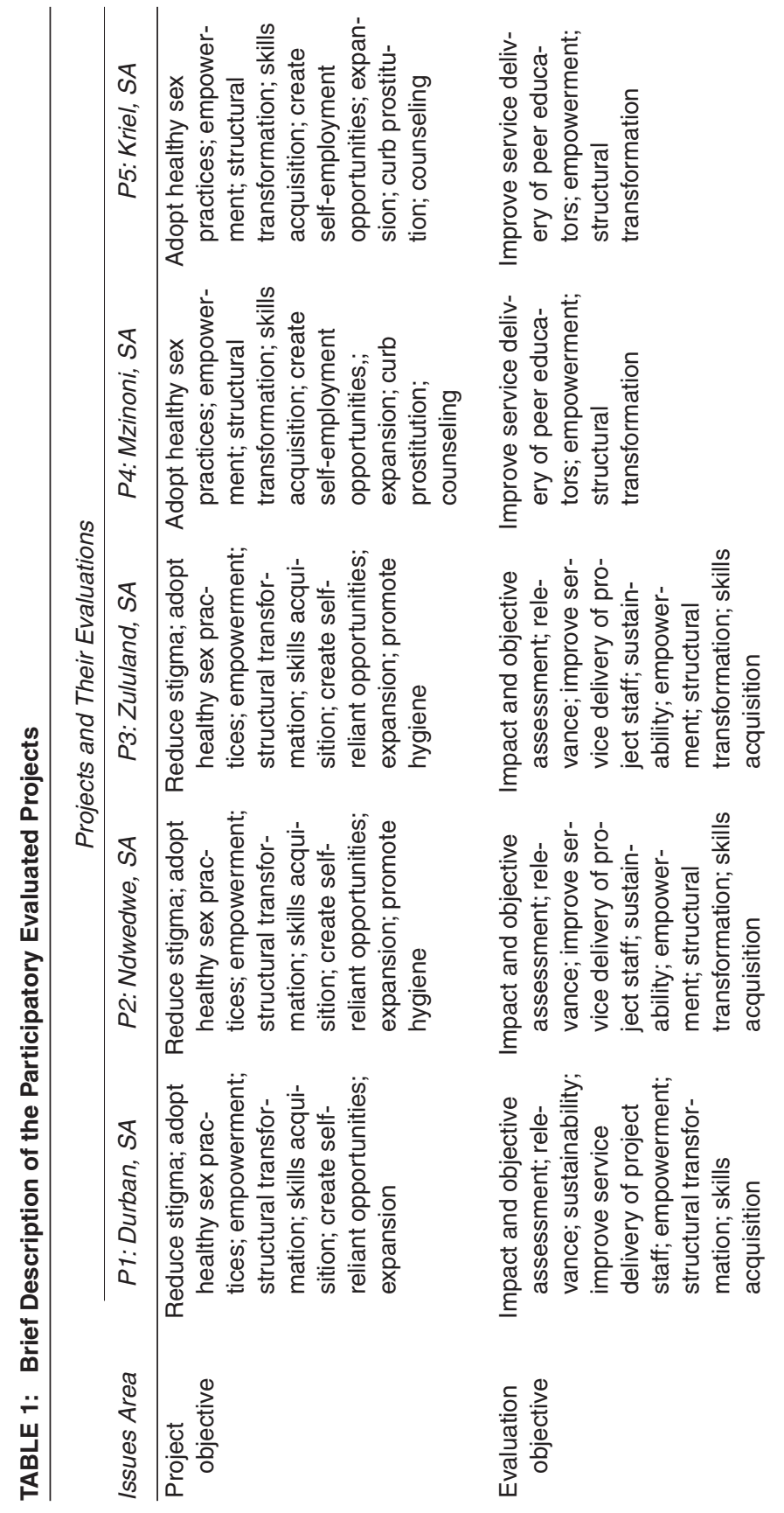




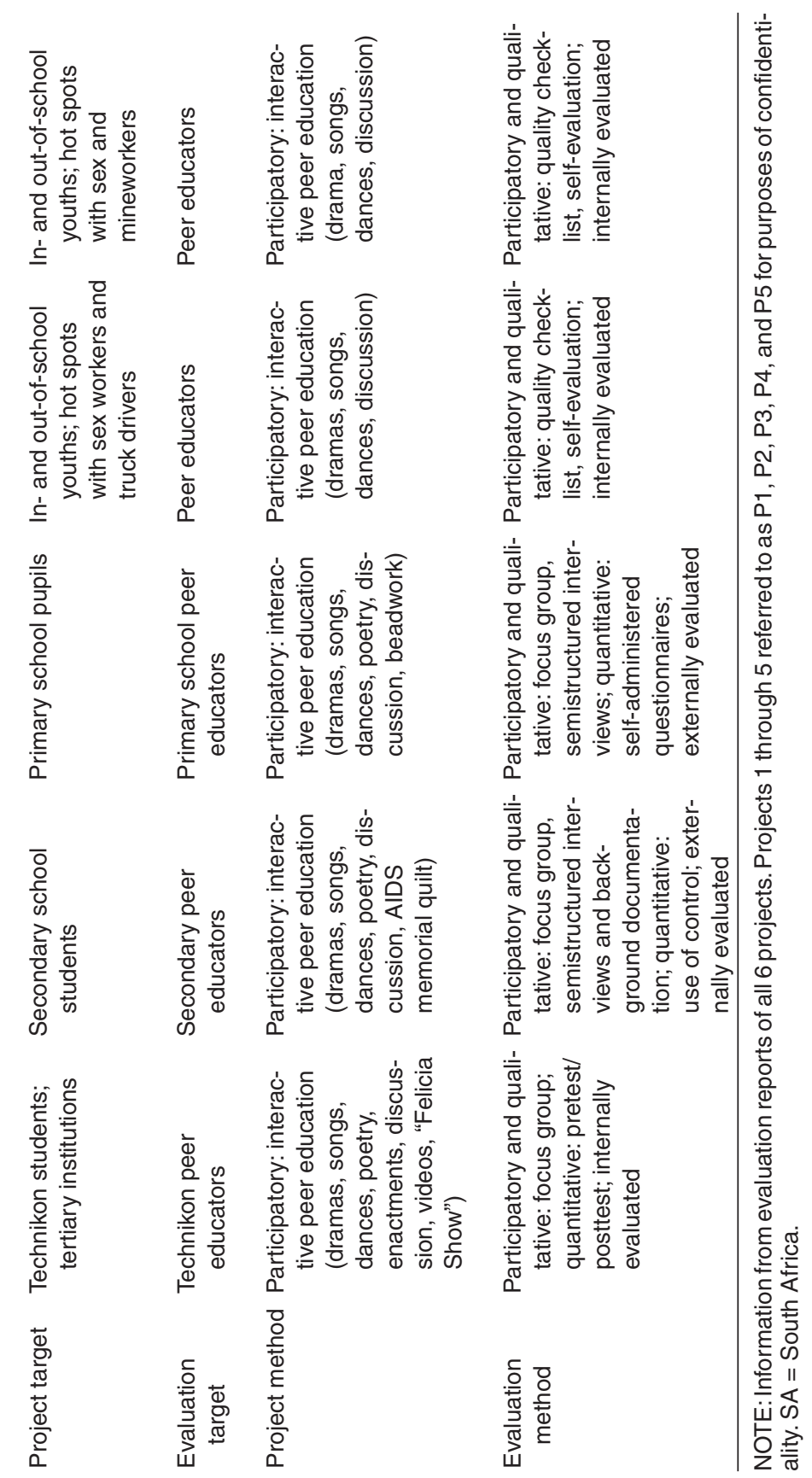


evaluation) was provided. Table 1 portrays many similarities in terms of the objectives of the projects and their evaluations and in terms of the methodology used (participatory). In terms of their objectives, similarities were noted in the general adoption of healthy sex practices, empowerment, structural transformation, skills acquisition, creation of self-reliant opportunities, and expansion of projects. These objectives, for easy understanding, were grouped as follows: knowledge acquisition, awareness, attitude change, empowerment, effective functioning, and sustainability. Certain background and practical implementation variations were evident as shown below.

Limitations arising from sociodemographic differences in the implementation and evaluation of the projects included gender, race, language, and age. The beneficiaries were all Black South Africans who could communicate most effectively in Zulu. They were of varying gender and age groupings. Beneficiaries of Projects 1, 2, and 3 (P1, P2, and P3) were made up of males and females within the age range of 12 to 18 years. P4 and P5 were made up solely of female beneficiaries, within the age range of 19 to 29 years.

All 5 projects had both female and male managerial staff members older than the age of 19 years. They were all Black South Africans who could communicate most effectively in Zulu. In terms of the evaluators, most of them $(80 \%)$ were females of whom $(60 \%)$ were of the White race and fluent in English (40\%) and Afrikaans (20\%). The other female evaluator was a Black South African Zulu speaker, and the lone male evaluator was a Coloured English speaker (Coloured refers to a population grouping made up of mixed racial descent, especially as distinguished during apartheid from Blacks, Asians, or Whites).

There is no doubt that when one examines the cultural and linguistic dynamics of the different parties in the 5 HIV/AIDS projects (beneficiaries, evaluators, and managerial staff), questions of uncertainties (answered later in the work) are raised, questions such as how the linguistic and cultural gaps between evaluators, for example, and beneficiaries are taken care of. This is especially important as $80 \%$ of the project evaluators cannot communicate effectively in Zulu, and the opposite is true of the beneficiaries whom they evaluate; they are all Black South Africans who can communicate most effectively in Zulu.

Limitations arising from differences in forms of evaluation (internal versus external evaluators) were thus: 3 projects ( $\mathrm{P} 1, \mathrm{P} 4$, and $\mathrm{P} 5$ ) were internally evaluated, and 2 projects ( $\mathrm{P} 2$ and $\mathrm{P} 3$ ) were externally evaluated. 


\section{PROJECT DESCRIPTIONS}

P1, P2, and P3 had as main targets both male and female Black South Africans (in-school youths in rural areas with the exception of P1, which had its schools in an urban area in Durban). Prior to visiting the mother schools, such as those in the areas shown in Table 1, some out-of-school youths were temporarily employed by the project (for the period of their training and performance), trained, and encouraged to perform drama and other activities in the schools. After that, a youth club was launched in each of these schools. The youth club members were then trained (by the project implementers) as peer educators to visit other schools (starting with the neighboring ones), perform there, and launch other youth clubs. They were encouraged to organize other activities such as AIDS festivals within their premises. During these festivals, students, parents, and other useful government and nongovernmental bodies were invited for networking. The youths were not on any stipend (formal or informal payroll) but were provided with refreshments after every performance. They were encouraged to provide ideas and means of generating their own sources of finance, such as the making of AIDS memorial quilts and beadwork.

P4 and P5 had as their main targets in- and out-of-school Black South African female youths (mostly those exposed to the practice of prostitution) in urban areas. The youths were divided into different groups depending on identified functions. A group of out-of-school youths implemented awareness campaigns (visits to hot spots such as shebeens [informal social halls], power stations, highways, and plantations, where prostitutes, truck drivers, or mineworkers met). The in-school youths organized awareness campaigns and counseling sessions within the schools. The project managerial staff (otherwise known as coordinators) trained the different groups of youths as peer educators. After the training, the out-of-school peer educators (those chosen for this project) carried out visitations to hot spots, where the peer educators engaged the people in discussions around HIV/AIDS through drama, songs, and dances. All the different groups of youths were on a stipend (informal payroll), and whenever they received any other form of employment, they were relieved of their duties as peer educators. They were also encouraged to come up with ideas and means of generating their own sources of finance, such as joint initiatives for which the project provided loans. 


\section{EVALUATION DESCRIPTIONS}

The evaluations were known to be part of the HIV/AIDS projects and treated as an integral part of the HIV/AIDS projects. They were separated only when deemed necessary to do so for the purposes of this study.

Evaluation of $P 1$. The evaluation took place with the peer educators of the two targeted tertiary schools. The main project managerial staff carried out the evaluation in an ongoing manner (after every training process and at the end of the academic year). The evaluation helped in assessing the impact of the project, finding out if the objectives of the project were reached, if the project was relevant to the recipients, and how services could be improved. It explored the perceptions of students regarding emergent trends and social development in the HIV/AIDS world. The evaluation also intended to empower the people, bringing about structural transformation (such as of learners to facilitators) within the project and skills acquisition.

Use was made of participatory methodology in the evaluation. The main project managerial staff used a focus group discussion (made up of both male and female peers) for the evaluation. In the discussion forums, the evaluator acted as a facilitator, eliciting personal responses. Preproject and postproject open-ended questionnaires were also administered to peer educators. Discursive interviews were conducted with key informants. After the completion of each part of the project (preparation, training, and implementation), reflection time, which was a feedback session, was conducted as part of the evaluation. Critical issues for discussion in the evaluation included the question as to whether positive living, gender issues, supportive environments, and interaction between people living with HIV/AIDS (PLAs) had been achieved, and how. Critical issues for discussion also included the training experiences of the peer educators and the value of the methodology used in the project. What, for example, made them (peer educators) happy or unhappy about the process of the project (if it was complex, simple, enjoyable, boring, creative, and entertaining) and why?

Evaluation of $P 2$. The evaluation took place with the peer educators at the different secondary schools. An independent body externally conducted the evaluation. This body was made up of five official members in the capacity of evaluators and a core of Zulu-speaking research assistants who were experienced in conducting focus group discussions, interviews, and preliminary data analysis. One of the official members, assisted by the Zulu-speaking assistants, conducted the evaluation. 
The evaluation focused mainly on assessing the impact of the project and finding out if the objectives of the project were met. It also focused on empowering the people, bringing about structural transformation and skills acquisition.

Use was made of similar methodology (participatory methodology) in the evaluation as that used in the project. Focus group discussions (made up of both male and female peers) were held at the schools where the projects had been implemented. In discussion forums, the research assistants acted as facilitators. Discursive questionnaires were issued to key informants, such as the trained teaching staff. The evaluation was conducted after the completion of the initial set of workshops and other follow-up activities. Critical issues for discussion in the evaluation included the question as to whether peer educators were sufficiently well trained, what they valued most about belonging to the club, what new things had been learned, how learners looked after themselves before and after the project, impact of life skills, any change in attitude toward PLAs, any translation of knowledge into actual changes in behavior, how members would feel about themselves if infected, had members disseminated the lessons learned and how, and any challenges and the way forward.

Evaluation of $P 3$. The evaluation of the HIV/AIDS project took place with the peer educators at the different project-targeted primary schools. An external evaluator conducted the evaluation. She did the evaluation in close collaboration with one of the Zulu-speaking managerial staff of the project. This staff member was well versed in conducting focus group discussions, interviews, and preliminary data analysis.

The evaluation focused mainly on assessing the impact of the project, its relevance, and finding out if the objectives of the project were met. It also focused on empowering the peer educators, bringing about structural transformation and skills acquisition. Use was made of similar methodology (participatory methodology) in the evaluation as that used in the project. Focus group discussions (made up of both male and female peers) were held at the schools where the projects had been implemented with a managerial staff member acting as facilitator. Semistructured interviews and questionnaires were issued to key informants, such as the trained teaching staff. Direct observations were made of learners participating in the activities such as launching new clubs. Critical issues for discussion in the evaluation included the question as to whether critical awareness among peers had been facilitated, if societal prejudices had been confronted, if peers had been empowered, if participatory teaching methodologies had been used, any cascading of activities, if opportunities to network had been created, any benefits from 
the project, change of attitudes toward sex and PLAs, development of appropriate skills, and how these things were achieved.

Evaluation of $P 4$. The evaluation was conducted with the different groups of peer educators, supervised by their coordinators. It was self-evaluation with the use of a quality checklist. The director of the project drew up a checklist. One of the coordinators (managerial staff) of each of the groups of peer educators helped in supervising the evaluation and in facilitating discussions resulting from the evaluation. After every visit to the hot spots, an evaluation was conducted. The evaluation helped mainly in improving service delivery, empowering the peer educators, and enhancing structural improvement of the project.

Evaluation of P5. The evaluation was conducted in a similar manner as $\mathrm{P} 4$ with the different groups of peer educators supervised by their coordinators. It was self-evaluation with the use of a quality checklist. One of the coordinators (managerial staff) helped in supervising evaluations and in facilitating discussions resulting from the evaluation. After every visit to the hot spots, the evaluation was conducted. The evaluation helped mainly in improving service delivery and empowering the peer educators.

\section{COMPARISON OF STATE OF BENEFICIARIES PRIOR TO AND AFTER IMPLEMENTATION/EVALUATION}

\section{AWARENESS AND KNOWLEDGE}

From evaluation reports, one gathered that irrespective of some differences, there was strong evidence to suggest that beneficiaries of all the HIV/ AIDS projects had become critically aware of health matters because of their participation in the club activities. These activities, which they felt gave them the opportunity to share their experiences and rehearse "real-life situations" (dramatized the reality of HIV/AIDS), thus enabled them to be more serious in measuring and assessing their behaviors.

In all the evaluation reports, it was spelled out that the beneficiaries used correct terminologies to speak knowledgeably of the "facts" about HIV/ AIDS and could link discussions to issues of sexually transmitted infections, prevention of HIV/AIDS transmission, ways in which the virus can be "slowed down," and many other health issues. In P1, P2, and P3, the evaluation reports revealed that beneficiaries were able, to a great extent, to 
contextualize discussions about HIV/AIDS and show sensitivity on ways to treat PLAs. They were aware of stigmatization and meaningfully spoke of the essence to minimize it and rather to show respect, love, and support to HIV/ AIDS sufferers.

In P3, the evaluation report, for example, revealed that one of the beneficiaries, prior to the workshops, thought HIV/AIDS was similar to influenza, with infected persons to be avoided. In the same report, it was held that beneficiaries had internalized the message of rights. Beneficiaries spoke with conviction and sincerity about "rights"- the rights of PLAs and the rights of girls to say "no." One of the pupils referred to it as "the constitution." To show the hunger in the hearts of the pupils to acquire as much knowledge as they could, P3 (similar to the other reports) highlighted the fact that in the group discussions, many relevant questions were asked. Also, group discussions ended naturally without any deliberate attempts on the part of the facilitators to do so. Babbie and Mouton $(2001,320)$ crowned the sharing of knowledge with the assertion that "the merging of this [local] knowledge and academic knowledge into a common field of knowledge permits the acquisition of a much more accurate picture, as well as a more profound understanding of a situation."

\section{ATTITUDES}

Similar to the extent of awareness and knowledge gained, attitude change was noted in all 5 projects. The evaluation report of $\mathrm{P} 1$ revealed that of every focus group with 13 to 15 members, at least 4 disclosed their status to the facilitators. They (those who disclosed their status) felt they were coping with HIV/AIDS as such, promising to publicly disclose their status in the coming year. There is no doubt that the number of those who disclosed their status is questionable in terms of reflecting the success of the project. When, however, one considers the background situation whereby prior to the HIV/ AIDS projects, the beneficiaries indicated that they were unbending about disclosing their status, the number of those who did disclose cannot be undervalued. In P2, one of the beneficiaries declared that HIV/AIDS was no longer "abstract" to him. In P4 and P5, the newly acquired values of the peer educators stand as an indication of the positive outcome of the projects. The reports of $\mathrm{P} 4$ and $\mathrm{P} 5$ revealed that the beneficiaries were in the main former prostitutes and some living with HIV who were conscripted from the communities (on a stipend) and trained to serve as peer educators. Hoshmand and O'Byrne (1996) alleged that reliable knowledge of the human and social world could only be achieved in the process of attempting to change that world and that 
genuine change can only occur when it is accompanied by shifts in the knowledge base of those concerned.

\section{EMPOWERMENT}

It was stated in all the evaluation reports that beneficiaries were empowered as a consequence of the way the projects were conducted (using elements of participation). They were empowered in varying ways. The P1 evaluation report revealed personal and group empowerment, with beneficiaries making mention of self-efficacy and group efficacy. As beneficiaries (of P1) put their individual efforts together to acquire and practice ways of fighting, for example, discrimination against those with HIV/AIDS, they reported gaining individual and group confidence to act. The evaluation reports of $\mathrm{P} 2$, $\mathrm{P} 3, \mathrm{P} 4$, and $\mathrm{P} 5$ also made mention of beneficiaries having been empowered to work as a team because of their acquisition of group confidence and selfconfidence. In addition, the $\mathrm{P} 3$ report indicated that the boys reported being empowered to act responsibly within relationships, for example, to be patient sex wise, respect the views of the other partner, "condomize," be open, and be faithful. Girls reported they had been empowered to uphold their rights in sexual relationships. Both genders indicated being empowered to make proper choices and decisions relating to sex, as well as taking responsibility for their health.

\section{EFFECTIVE FUNCTIONING}

The different evaluation reports on the whole revealed that effective functioning in the area of strengthening collaborative relationships at all possible levels or having full participation of all concerned parties was achieved to a relatively high extent. The implementers of all the HIV/AIDS projects were noted to be acting in a new way as facilitators: willing to give as well as to receive. It was, for example, highlighted in the evaluation report of $\mathrm{P} 3$ that one of the beneficiaries commended the facilitator as a good role model in terms of the way she conducted herself. Babbie and Mouton (2001, 358) commended such behavior; according to them, the role of an implementer (project implementer/evaluator) should be "that of a methodological consultant and facilitator ... responsible for building relationships with the participants on the basis of shared trust. Just like the participant, he/she is a learner and a non-imperialistic teacher."

Effective functioning via networking was also noted to be relatively high. In P1, P2, and P3, there was networking with stakeholders such as the 
teaching staff who participated in the workshops. During the launching of the youth clubs, the continued participation and collaboration of the principals of the schools, students and pupils, teaching staff, governing body members, representatives from welfare services, and teachers from the other schools of the area were registered. In P4 and P5, the peer educators networked with hot spot owners and with similar peer educators in other areas. They met regularly, and those more experienced were placed with those of lesser experience to build up one another. The authenticity of such an approach was held by Fals-Borda and Rahman $(1991,5)$ to be deeply "rooted in cultural traditions

of common people ... resplendent with feelings and attitudes of an altruistic, co-operative and communal nature and which are genuinely democratic."

\section{SUSTAINABILITY}

In terms of financial sustainability, it was seen to be quite challenging. Nonetheless, in P1, P2, and P3, the evaluation reports revealed that the beneficiaries were said to be orientated toward self-employment by the making of HIV/AIDS memorial quilts and beadwork. The P4 and P5 evaluation reports revealed that the beneficiaries were prostitutes who were employed on voluntary bases for a stipend. When they as a group came up with a project to earn a living, they were provided with a loan. They (beneficiaries) also contributed money on a regular basis to lend out. One of the roles of employment, stated by the project director (P4), was that if in due course someone got a job, she had to give up her position so that another prostitute out there in the "blue" could be given an opportunity for change as well.

In all the HIV/AIDS projects, there were indications of activities having been expanded. Reports of P1, P2, and P3 revealed expansion of their activities through club launchings, visitations to neighboring schools, and the "open day" in mind for the coming year. For P4 and P5, the reports mentioned the peer educators expanding their territories to include more hot spot owners, mineworkers, and prostitutes, making regular visits to act, sing, and dance.

The above comments (per variable) were further reinforced by the results of the focus group discussions conducted by the researcher with the beneficiaries. Because of the excitement, beneficiaries spoke unanimously of the different ways in which they participated in their projects, for example, in songs, drama, and discussions. Knapp, Stohl, and Reardon (1981, 32) revealed that "when the recipient is required to participate in forming the message, even if it is only to fill in implicit premises, the chances of perceiving the message as important—would seem to be greatly improved." Taking 
the example in P1 in which a show was conducted known as "Felicia Show," one of the beneficiaries said that the show was like bringing the television live to them, and they were able to discuss serious matters among themselves in a lively way. When acting, said another beneficiary, "I could feel like I was truly HIV/AIDS positive." Two (40\%) of the focus group members (still in P1) confirmed the reflective technique of songs, drama, and discussions deepening their understanding of the essence of HIV/AIDS testing to the extent that they went for it. One said he used to distance himself from his HIV/AIDS-positive friends but stopped as a result of the impact of the project on him. A beneficiary in $\mathrm{P} 2$ who would not eat with a spoon used by an HIV/AIDS patient (for fear of getting infected) admitted doing so after the HIV/AIDS project.

In $\mathrm{P} 3,100 \%$ of the peer educators promised abstention from premarital sex. When the researcher asked why, one of the beneficiaries said because there were no condoms in their sizes. The researcher then tried to find out whether, if condoms were made in their sizes, they would engage in premarital sex. The rest of the group said no because from the project they had come to know the dangers of HIV/AIDS too well to venture into any risky practice. All (100\%) of the beneficiaries of P4 and P5 admitted that the projects had changed their lifestyles: Once they were prostitutes, but now they were peer educators and knew better.

During the interview sessions, interviewees likewise confirmed the expansion of the different project activities (drama, songs, dances, discussions) as reported in the evaluation reports. The beneficiaries talked of taking the lessons learned to the communities and to their families and friends. One talked of constantly briefing the mother of their discussions, the other of being a "student nursing aid assistant" and helping in many ways to assist the students by making sure they took their medications when ill. In P2 and P3, the members talked of their youth clubs expanding their activities to include cleaning campaign projects: Toilets were kept clean, toilet rolls were supplied, and littering of the environment was checked. They even talked of going to companies to solicit for supply of toilet rolls. These activities, according to what they learned, were linked to HIV/AIDS given that cleanliness, for example, helps prevent diseases. In P4 and P5, the peer educators talked of accompanying some of the patients to the clinic, besides counseling and providing condoms to them.

With respect to the evaluations, the benefits of a collaborative relationship and the sharing of experiences were also reiterated. Beneficiaries of all the focus groups in the different evaluations unanimously proclaimed that the participatory process (focus group discussion) of the evaluation served as a learning process to them: a process that enabled them to pick up vital issues 
of the project that they had forgotten or overlooked but were brought to light by other members of the group. In fact, one of the interviewees of the focus group of P1 (similar to the others) told the researcher that the focus group evaluation made her "to see where others were at": a discovery that made her reevaluate her stand on HIV/AIDS prevention. Guba and Lincoln (1989), in their description of fourth-generation evaluation, applauded such a method of learning as, according to them, it operated within sociocultural/political factors, within a joint collaborative, teaching, and learning process and within a process that creates reality.

The evaluations were also said to have helped in enhancing the selfemployment strategies and expansion of the projects' activities. During the focus group discussions, ideas on how to strengthen sustainability were shared. In addition, peer educators of P4 and P5 held that after each performance session, as mentioned earlier, they returned to discuss as a group their strengths and challenges, as well as ways of improving. Once improvement strategies were put in place, they then went out to implement them through visitations to hot spots, thus guaranteeing service quality and continuation.

Beneficiaries were satisfied and excited in response to the way the HIV/ AIDS projects and their evaluations were conducted. This can be argued to be indicative of the interventions' value, usefulness, and meaningfulness to the beneficiaries. In an "Evaluation Standards Committee" deliberation document, Stufflebeam reported, "An evaluation should not be done at all if there is no prospect for it being useful to some audience" (quoted in Patton 1982, 297). On the other hand, when recipients were able to relate the value, meaningfulness, and usefulness of something to their situations, the likelihood of change was seen to be greater. The different areas in which beneficiaries acquired skills in both project implementation and evaluation (with the exception of acting talent that was acquired at project implementation) could be summarized to include the following:

- acting talent;

- communication skills: debating, discussions, acknowledgment, and persuasive techniques;

- leadership skills and organizational skills;

- problem-solving, negotiation, and decision-making abilities;

- learning via activities;

- cooperation and sharing of resources abilities;

- life skills and ways of teaching learners about it;

- showing of sympathy; and

- listening, observational, and assertive skills. 


\section{DISCUSSION AND CONCLUSIONS}

Judging from the above, it was noticed that irrespective of the different background situations projected in all the HIV/AIDS projects, positive change took place. This reflected that the background situations of the projects (such as gender, age, and language differences and internal versus external forms of evaluation) had minimal negative impact on the projects. It should, however, be noted here that certain conscious efforts were made by the implementers of the different projects to minimize the effect of these background situations on the projects. Examples of such efforts included the selection of managerial staff to be concomitant to the beneficiaries: Managerial staff of the different projects were of the same race and language groups as those of the beneficiaries. The managerial staff members of the different projects were, in the main, Black South Africans who besides their capability of communicating in English could effectively communicate in Zulu, as did the beneficiaries.

In cases of mixed races, different, alternative arrangements were made. The internal evaluators of $\mathrm{P} 1$ and $\mathrm{P} 5$, although of different race and language groupings (Coloured English and White Afrikaans respective speakers) could also communicate in the language of the beneficiaries (Zulu). In P2, the external White English speaker, who could not communicate in the language of the beneficiaries (Zulu), worked with trained Black Zulu speakers as field assistants. In P3, the external evaluator (White English speaker) did likewise by working closely with one of the Black South African managerial staff of the project.

Fishbein $(2000,275)$ held that any given behavior is likely to occur "if one has a strong intention to perform the behaviour, if one has the necessary skills and abilities required to perform the behaviour, and if there are no environmental constraints preventing behaviour performance." From the identified skills and the overall minimal environmental or background impact of the projects on the beneficiaries, change was, on the whole, noticed. The summary of this is as follows:

- acceptance of social responsibility;

- awareness of the necessity to challenge stereotypes and ability to now do so;

- accept, care, and love HIV-positive people;

- "HIV/AIDS became more simple than being abstract because of our facilitators organized people already living with virus" (P3);

- can talk freely about sexuality and HIV/AIDS;

- can say "no" to unwanted or unprotected sex offers; 
- can muster strength and courage to abstain from sex until marriage, be faithful, and "condomize" if need be; and

- see the necessity to reach families, friends, and the community with lessons learned.

This evidence can thus be argued to override to a great extent the criticism of nonformal educational development project implementation and evaluation in the Third World. This criticism has been advanced by Brunner and Guzman (1989, 9), indicating project implementation and evaluations reflected "the world-view and priorities of the sponsoring agencies and denied any meaningful input from the main actors in the . . projects." In the HIV/AIDS projects and evaluations studied, beneficiaries identified the different areas in which they had been empowered, made aware of their abilities to muster for social action, and areas in which they had acquired skills. The situation of powerlessness that Freire (1970) described as that which people play the role of an object that is acted on rather than a subject that is acting in and on the world was therefore counteracted. On the whole, instead of beneficiaries citing situations in which they or others undervalued their opinions, they rather cited instances in which they were empowered and equipped for social action and in which the community looked to them for help.

All in all, judging from the validity of the outcomes and wider social impacts, one can say that the degree and quality of beneficiary involvement in project implementation and evaluation generated beneficiary excitement and a general sense of project ownership, all of which was noted to create an enabling environment for the making of proper choices and decisions.

On the other hand, when group participation was encouraged in implementation and evaluation of projects (such as those examined in this study), it contributed to overriding to a great extent limitations arising from sociodemographic differences (project locations and gender, language, and age and race of implementers, evaluators, and beneficiaries) in the attainment of project objectives. It also overrode, to a great extent, limitations arising from differences in forms of evaluation (internal versus external evaluators) and in the assessment of project objectives while at the same time successfully promoting social change.

All the participatory projects were effective in meeting their objectives, irrespective of the internality or externality of the evaluation, because of the participatory nature (group discussions, situation enactment, and others) of the evaluations. 


\section{REFERENCES}

Babbie, E., and J. Mouton. 2001. The practice of social research. Cape Town, South Africa: Oxford University Press.

Brunner, I., and A. Guzman. 1989. Participatory evaluation: A tool to assess projects and empower people. In International innovations in evaluation and methodology: New directions for program evaluation, ed. R. Connor and M. Hendricks, 9-17. San Francisco: JosseyBass.

Bruyn, T. 1998. HIV/AIDS and discrimination. Montreal: Canadian HIV/AIDS Legal Network and Canadian AIDS Society.

Cohen, L., and L. Manion. 1989. Research methods in education. New York: Routledge.

Fals-Borda, O., and M. Rahman. 1991. Action and knowledge: Breaking the monopoly with participatory action-research. New York: Apex.

Fishbein, M. 2000. The role of theory in HIV prevention. AIDS Care 12 (3): 273-78.

Freire, P. 1970. Pedagogy of the oppressed. Harmondsworth, UK: Penguin.

Guba, E., and Y. Lincoln. 1989. Fourth generation evaluation. Newbury Park, CA: Sage.

Hoshmand, T., and K. O'Byrne. 1996. Reconsidering action research as a guiding metaphor for professional psychology. Journal of Community Psychology 24:185-200.

Knapp, L., C. Stohl, and K. Reardon. 1981. Memorable messages. Journal of Communication 31 (4): 27-41.

Musendo, D. 2003. Lessons from capacity development in HIV/AIDS communication. Database. http://www.healthcomms.org/comms/capacity/cy03.html (accessed January 18, 2004).

Nutbeam, D. 1998. Evaluating health promotion: Progress, problems and solutions. Health Promotion International 13:27-44.

Patton, Q. 1982. Practical evaluation. Beverly Hills, CA: Sage.

Mercy Bi Niba holds a Ph.D. from the University of KwaZulu Natal, Pietermaritzburg, South Africa. At present, she is a postdoctoral researcher of the Discipline of Community Resources, University of KwaZulu-Natal. Her research interest lies in methodologies used in the implementation and evaluation of communication-based projects, particularly HIV/AIDS projects and participatory methodologies.

J. Maryann Green holds a Ph.D. from Oklahoma State University. At present, she is a professor and the head of Discipline of Community Resources, University of KwaZulu-Natal, Pietermaritzburg, South Africa. She lectures in community development, and her research interests lie in renewable energy and development, technology-human interface relationships, gender issues, development project evaluation, and entrepreneurship. 